\title{
APPLICATION OF SUSTAINABLE DESIGN PRINCIPLES TO INCREASE ENERGY EFFICIENCY OF EXISTING BUILDINGS
}

\author{
B. MANSOURY ${ }^{1}$, H. R. TABATABAIEFAR ${ }^{2}$
}

\begin{abstract}
This study investigates the effectiveness of different energy retrofitting techniques and examines the impact of employing those methods on energy consumption of existing residential buildings. Based on the research findings, the most effective and practical method of retrofitting has been proposed in order to improve energy efficiency of existing buildings. In order to achieve this goal, an existing residential building has been simulated in FirstRate 5 software so as to determine the existing thermal performance of the building. Afterwards, considering sustainable design principles, different insulation layers, glazing, and construction materials have been employed to conduct a comprehensive thermal performance study. Based on the research outcomes, the best technique for increasing energy efficiency of existing buildings and reducing their environmental impact and footprint has been identified and proposed for practical purposes.
\end{abstract}

Keywords: energy consumption, residential building, sustainable design principles, thermal performance

\section{Introduction}

Energy issues have been a growing concern in recent decades. Limited energy resources and increasing energy consumption from one side and environmental pollution and waste of resources from the other side have substantially affected the future of human life. In this regard, buildings (residential and commercial) consume approximately 40 percent of the total annual energy in most countries (IEA, 2015) and produce about 26 percent of annual greenhouse gas emissions (EPA, 2013). For instance, about 50 percent of the UK's greenhouse gas emission is attributable to the energy used in buildings (Mithraratne, 2007). In Australia, approximately 25 percent of the total energy is consumed by buildings and households are directly responsible for about one-fifth of greenhouse emissions (Department of Industry, 2013). An average Australian home emits about 7 tonnes of greenhouse gas each year showing that most Australians live in houses that work against the climate not with it (McGee et al., 2008). Around 40 percent of total energy consumption of Australian buildings goes to heating and cooling due to the low thermal performance of the buildings (DWHA, 2008). Thermal performance of buildings determines the amount of energy used for heating and cooling of the buildings which profoundly influences energy efficiency. Employing sustainable design principles and effective use of construction

\footnotetext{
${ }^{1}$ Faculty of Design, Architecture and Building, University of Technology Sydney (UTS), Australia

${ }^{2}$ Faculty of Science and Technology, Federation University Australia, Mt Helen Campus, PO Box 663 Ballarat VIC 3353, Australia, e-mail: h.tabatabaiefar@federation.edu.au
} 
materials can play a crucial role in improvement of thermal performance of new and existing buildings (Lyons and Reardon, 2013).

Before the oil crisis of 1973, the energy efficiency of envelop building components was rarely considered as an important factor in building design and construction (CRES, 2000). As a result, significant portion of existing houses, older than 40 years, constructed without considering energy efficiency. Some of these existing buildings are a part of cultural heritage, so importance of preserving them is apparent while considerable numbers of those buildings are ordinary buildings with no cultural heritage value. Demolishing and replacing existing ordinary old buildings with new ones may seem to be a good solution for increasing energy efficiency of the existing buildings. However, the required amount of energy and time for this process would make it absolutely uneconomical. Hence retrofitting those buildings would be the best approach to improve their energy efficiency. Energy retrofitting of existing buildings can be a remedial method to improve energy efficiency and to reduce their environmental impact and footprint.

\section{Energy Retrofitting Method of Building Envelops}

The energy consumption for heating and cooling is normally determined by the quality of the building envelops. Building envelops are the parts of building which separate the habitable areas from exterior environment. Building envelops consist of external walls, external doors, windows, roof, ground and the internal walls that separate conditioned spaces from noncondition spaces. The energy loss from the building envelops is the key factor. Heat loss through conduction, convection and radiation from building envelops. Therefore, thermal performance of the building envelops should be improved by using different methods of retrofitting. In this study, the methods of retrofitting have generally been divided into four categories, including energy retrofitting of external walls, roofs and ceilings, floors, and windows.

\section{Characteristics of Benchmark Building}

In this study, an existing building located in Melbourne city, Victoria (Australia) has been selected to serve as the benchmark building for modelling and simulation purposes. Figure 1 illustrates the floor plan of the benchmark building.

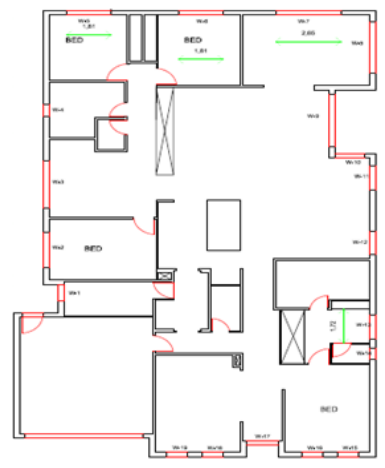

Figure 1. Floor plan of the benchmark building located in Melbourne 
The benchmark building is a single dwelling with total floor area of $273 \mathrm{~m}^{2}$ consisting of four bedrooms as well as rumps living room, leisure room, family room and kitchen. It also has $36 \mathrm{~m}^{2}$ garage which does not influence the calculations in this study. Total opening area for the building is about $43 \mathrm{~m}^{2}$. The 3 dimensional model and orientation of the building are shown in Figure 2.

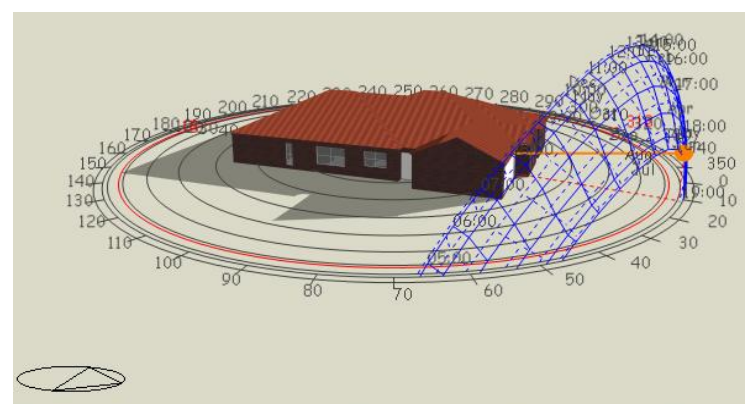

Figure 2. 3-dimensional model and orientation of the benchmark building

As illustrated in Figure 3, the building is resting on a $150 \mathrm{~mm}$ thick reinforced concrete ground slab and $19 \mathrm{~mm}$ thick timber flooring has covered the top of the concrete slab. Therefore, there is $90 \mathrm{~mm}$ airspace gap between the slab and the timber floor which can be used to install additional insulation. R-values of the flooring system components have been determined based on ABCB (2014) and summarised in Table 1.

Table 1. R-values of flooring system components

\begin{tabular}{|c|c|c|c|}
\hline Item & Item description & Thickness $(\mathrm{mm})$ & R-value $\left(\mathrm{m}^{2} \mathrm{k} / \mathrm{w}\right)$ \\
\hline 1 & Indoor Air film & - & $\begin{array}{c}0.016 \text { in summer time } \\
0.011 \text { in winter time }\end{array}$ \\
\hline 2 & Timber floor & - & 0.12 \\
\hline 3 & Air space & 90 & 0.17 \\
\hline 4 & Concrete slab & 150 & 0.104 \\
\hline 5 & Ground & - & 0.56 \\
\hline
\end{tabular}

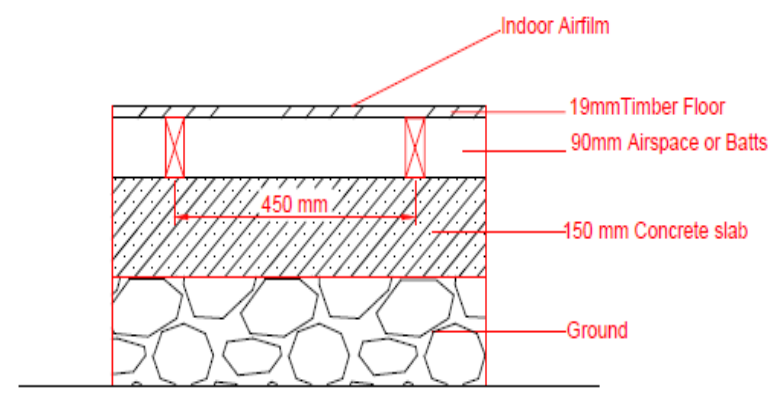

Figure 3. Benchmark building floor details 
Existing external walls of the benchmark building are brick veneer. Those walls consist of single exterior brick wall supported by a timber or metal frame (stud) covered with an internal wall lining material as well as plasterboard. Details of the exiting walls consist of $10 \mathrm{~mm}$ plasterboard, $90 \times 60 \mathrm{~mm}$ timber studs and $110 \mathrm{~mm}$ brick wall without any insulation as shown in Figure 4. R-values of the wall components have been determined based on ABCB (2014) and summarised in Table 2.

Table 2. R-values of brick veneer wall components

\begin{tabular}{|c|c|c|c|}
\hline Item & Item description & Thickness $(\mathrm{mm})$ & R-value $(\mathrm{m} 2 \mathrm{k} / \mathrm{w})$ \\
\hline 1 & Indoor Air film & - & 0.12 \\
\hline 2 & Plasterboard & 10 & 0.06 \\
\hline 3 & Cavity and Air space & 90 & 0.17 \\
\hline 4 & Masonry & 110 & 0.17 \\
\hline 5 & Outdoor Air film & - & 0.04 \\
\hline
\end{tabular}

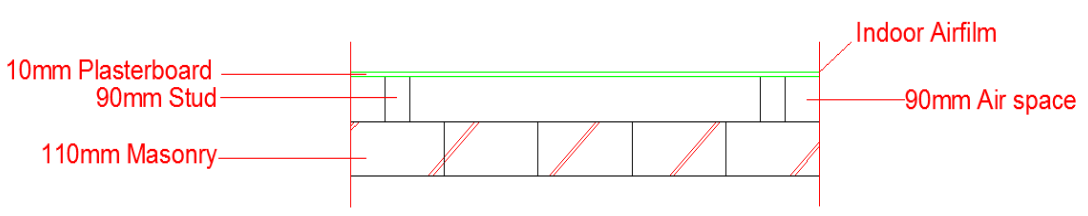

Figure 4. Benchmark building brick veneer wall details

The roof consists of clay tiles roof 25 degree pitch with horizontal ceiling and without any insulation. This roof has a medium colour and the ceiling consists of $10 \mathrm{~mm}$ plasterboard. R-values of the roof and ceiling components have been determined based on ABCB (2014) and summarised in Table 3.

Table 3. R-values of roof and ceiling components

\begin{tabular}{|c|c|c|c|}
\hline Item & Item description & Thickness $(\mathrm{mm})$ & R-value $\left(\mathrm{m}^{2} \mathrm{k} / \mathrm{w}\right)$ \\
\hline 1 & Outdoor air film $(7 \mathrm{~m} / \mathrm{s})$ & - & 0.03 \\
\hline 2 & Roof clay tile & - & 0.02 \\
\hline 3 & Roof airspace & 100 & 0.18 \\
\hline 4 & Plasterboard gypsum & 10 & 0.06 \\
\hline 5 & Indoor Air film & - & 0.14 \\
\hline
\end{tabular}

\section{Computer Modelling and Simulation}

FirstRate 5 software has been utilised in this study to model and estimate the annual heating and cooling energy usage of the benchmark building. This software is an interactive tool with a graphic user interface that enables designers and thermal performance assessors to generate energy ratings for a home by tracing over floor plan. This software also uses the same 
underlying calculation engine that was designed by Commonwealth Scientific and Industrial Research Organisation (CSIRO). As the first step of modelling, climate data have been introduced to the software by defining and entering Melbourne area climate data. Then, as illustrated in Figure 5, floor plan has been drawn in AutoCAD and imported to the software adoptable format.

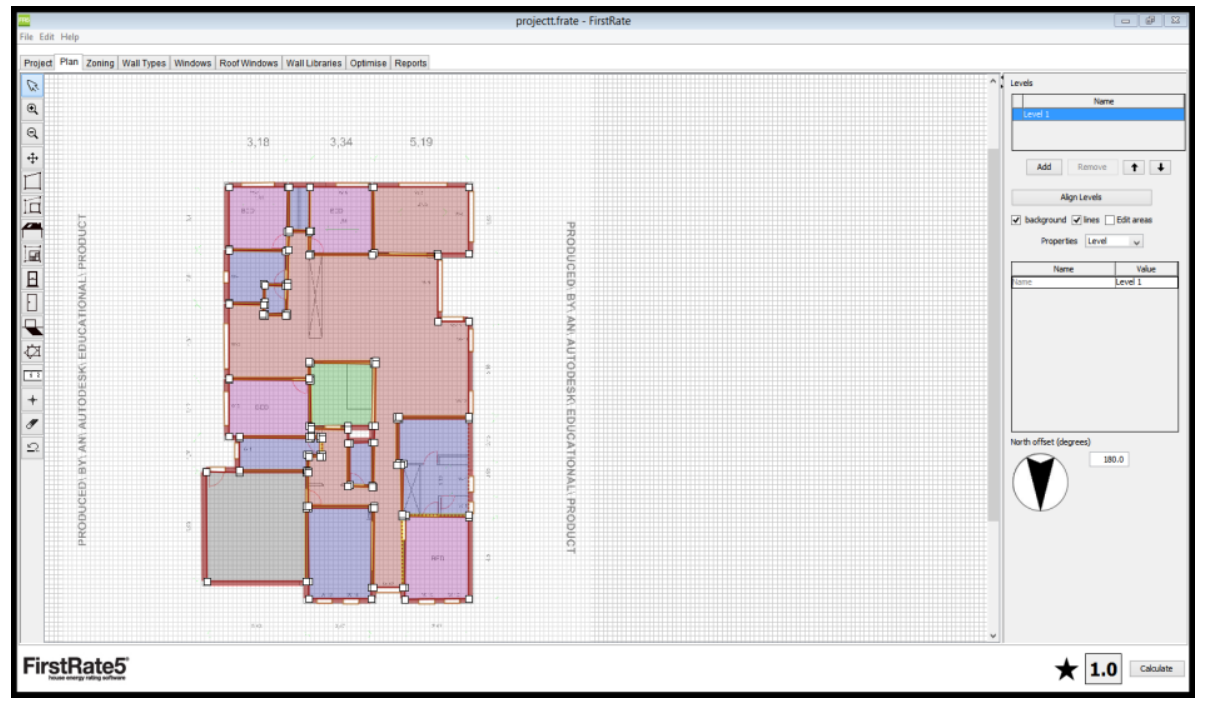

Figure 5. Floor and zoning plan in FirstRate5

Therefore, geometric details of the floor plan can be read and interpreted precisely by the software. Afterwards, five different zone classifications have been introduced to the program and assigned to each zone of the building considering type of occupancy, internal heat generation and ventilation as summarised in Table 4. Each occupancy zone is shown with different colour in Figure 5.

Table 4. Different zone classifications

\begin{tabular}{|l|l|}
\hline \multicolumn{1}{|c|}{ Type of zone } & \multicolumn{1}{c|}{ Details of occupancy } \\
\hline Living & Conditioned from 7-24. Daytime occupancy. No cooking heat gain. \\
\hline Bedroom & Conditioned from 16-9. Night-time occupancy. \\
\hline Kitchen & Conditioned from 7-24.daytime occupancy. Cooking heat included. \\
\hline Other (daytime usage) & If heat and or cooled, conditioned from7-24. No occupancy heat gain. \\
\hline Other (night-time usage) & If heated and or cooled, conditioned from 16-9. No occupancy gains. \\
\hline Garage & No conditioned in this research \\
\hline
\end{tabular}

As the last step, R-values for different building components have been extracted from Tables 1, 2 and 3 and assigned to different components of the computer model manually. 
R-values for all other components such as windows, doors, and ceiling fans were selected from the default program component values. Timber single-glazed frame with clear glass and Holland blind were selected for all windows and doors. Also, Hidden roof space and subfloor zones are automatically generated by the program.

In the end, annual energy usage analysis has been carried out by the software based on the defined geometry, zoning, and R-values. Eventually, as shown in Figure 6, calculated total energy consumption of the benchmark building for one year is $455.5 \mathrm{MJ} / \mathrm{m}^{2}$ for heating and cooling. From this amount of energy, $376.5 \mathrm{MJ} / \mathrm{m}^{2}$ is used for heating and $79 \mathrm{MJ} / \mathrm{m}^{2}$ for cooling, respectively. At this step, the building has obtained one star of energy rating.

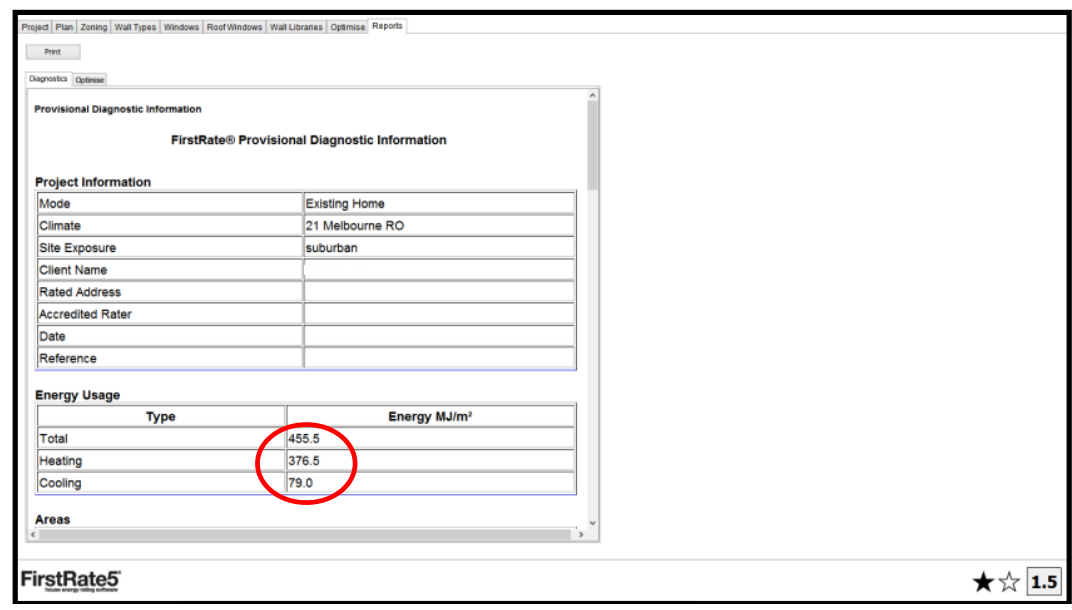

Figure 6. FirstRate5 annual energy consumption analysis outcomes

\section{Retrofitting and Improvements}

Retrofitting is improving thermal performance of the building by installing different systems or using different methods and materials. At retrofitting stage, the benchmark building has been assumed to be retrofitted using different remedial techniques based on sustainable design principles. The outcomes of employing different methods will be compared and examined in order to identify the most efficient remedial solution for improving the energy performance of the benchmark building. Five main remedial techniques have been considered for this purpose as follows:

Method 1: Adding insulation to external walls. A layer of Rockwool batt insulation with $\mathrm{R}$-value equal to 2.5 is placed between the plasterboard and brick wall and named BV 2.5.

Method 2: Adding insulation at the level of ceiling. Layers of insulation blanket with different R-values including 1, 2.5, 3, 4, 5, 6, and 7 are installed on top of the ceiling plasterboard at the roof hidden space and called CB1 to CB7, respectively.

Method 3: Combination of method 1 and 2. In this method, BV2.5 and CB4 are combined.

Method 4: Replacing the windows and optimising air leakage. All single glazed timber framed windows replaced once by uPVC double glazed windows with $3 \mathrm{~mm}$ clear glass and $6 \mathrm{~mm}$ Air gap having U-value of 3.58 and the next time by uPVC 
double glazed with $5 \mathrm{~mm}$ energy advanced glasses with $12 \mathrm{~mm}$ Argon gap having U-value of 1.83 .

Method 5: Adding a layer of insulation with $\mathrm{R}$-value of 2 in addition to a layer of reflective insulation on the floors.

Based on the above mentioned methods, 12 different modes have been introduced to the computer model as follows:

Mode 1: Benchmark building without insulation;

Mode 2: Retrofitted walls with BV 2.5;

Mode 3: Retrofitted roof with R2.5 insulation;

Mode 4: Retrofitted roof with R3 insulation;

Mode 5: Retrofitted roof with R4 insulation;

Mode 6: Retrofitted roof with R5 insulation;

Mode 7: Retrofitted roof with R6 insulation;

Mode 8: Retrofitted roof with R7 insulation;

Mode 9: Retrofitted walls with BV2.5 and R4 ceiling insulation;

Mode 10: Replacing windows, uPVC double-glazed $6 \mathrm{~mm}$ air gap;

Mode 11: Replacing windows, uPVC double-glazed with $5 \mathrm{~mm}$ glasses and $12 \mathrm{~mm}$ Argon gap; and

Mode 12: Retrofitted floors with R2 insulation and one layer of reflective foil.

\section{Results and Discussions}

Annual energy usage analysis has been carried out using FirstRate 5 software to determine heating and cooling energy consumption of the benchmark building for all 12 mentioned modes. Then, the results of employing different modes have been tabulated in Table 5 and graphical representation of the results illustrated in Figure 7. Those results have been compared and examined in order to identify the most efficient remedial solution for improving the energy performance of the benchmark building.

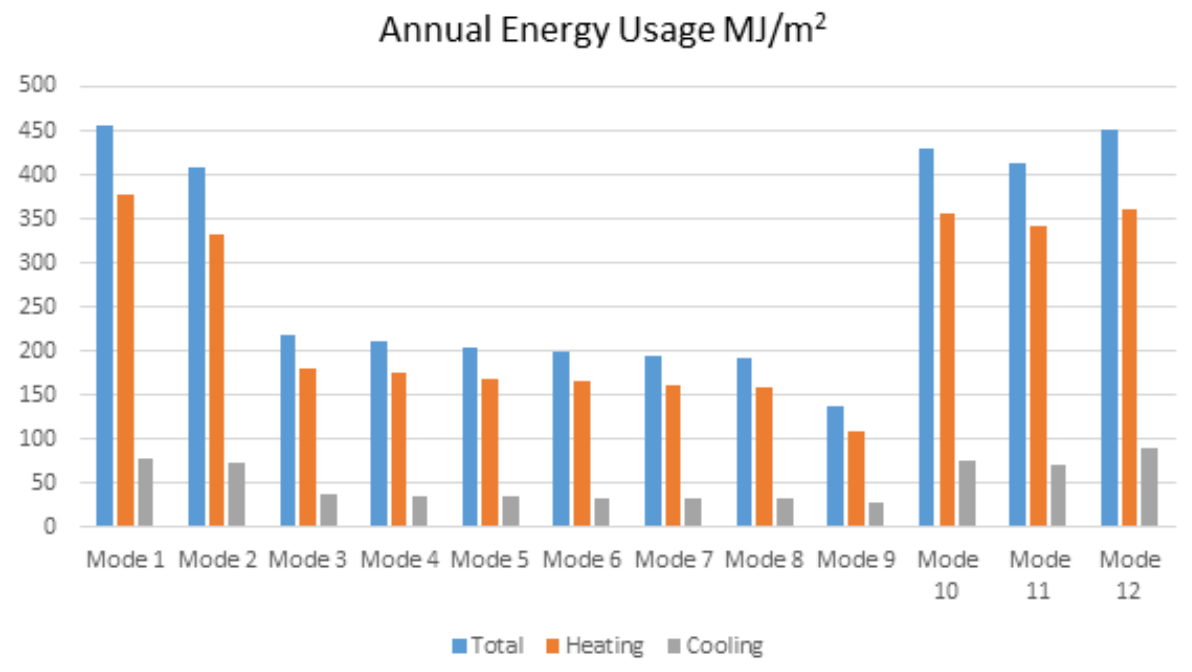

Figure 7. Graphical representation of annual energy consumption for each mode 
Table 5. Annual energy usage analysis results and star ratings for 12 different modes

\begin{tabular}{|l|c|c|c|c|}
\hline \multirow{2}{*}{ Modes } & \multicolumn{2}{|c|}{ Annual Energy Consumption $\mathrm{MJ} / \mathrm{m}^{2}$} & \multirow{2}{*}{ Star rating } \\
\cline { 2 - 4 } & Total & Heating & Cooling & \\
\hline Mode 1 & 455.4 & 376.4 & 79 & 1.5 \\
\hline Mode 2 & 407.7 & 333.5 & 74.2 & 1.8 \\
\hline Mode 3 & 218.7 & 181.5 & 37.2 & 3.6 \\
\hline Mode 4 & 212.3 & 176.2 & 36.1 & 3.7 \\
\hline Mode 5 & 204.2 & 169.3 & 34.9 & 3.9 \\
\hline Mode6 & 198.8 & 165.0 & 33.8 & 3.9 \\
\hline Mode 7 & 195.5 & 162.1 & 33.4 & 4 \\
\hline Mode 8 & 193.0 & 159.9 & 33.1 & 4 \\
\hline Mode 9 & 137.3 & 108.5 & 28.9 & 5.3 \\
\hline Mode 10 & 430.1 & 355.4 & 74.7 & 1.7 \\
\hline Mode 11 & 412.4 & 341.5 & 70.9 & 1.8 \\
\hline Mode 12 & 450.8 & 360.6 & 90.2 & 1.5 \\
\hline
\end{tabular}

Comparing the results, it becomes apparent that Mode 1 (existing condition of the benchmark building) has the maximum energy consumption while Mode 9 (retrofitted walls with BV2.5 and R4 ceiling insulation) has the minimum energy usage per year among the other modes. Therefore, it is understood that Mode 9 is the most efficient measure to improve the thermal performance of the benchmark building. It is also observed that Mode 12 of retrofitting (retrofitted floors with R2 insulation and one layer of reflective foil) is the most ineffective technique for improving energy usage of the building.

Consequently, the use of insulation layer with R2.5 in the external walls and adding R4 insulation layers in the ceiling together seems to be the most effective method of retrofitting for the current building. However, feasibility of employing this technique is an important challenge during retrofitting process. Insulation in existing brick veneer walls requires the plasterboard to be removed which causes some damage to the building. Therefore, this type of retrofitting can be unreasonably expensive. On the other hand, it is possible to add insulation to almost all common roof types in Australia. Ceiling insulation technique is a simple to fit method if the roof space is accessible and it can be considered very cost effective comparing to other techniques.

Table 6 and Figure 8 demonstrate annual energy consumption improvement by increasing the thermal resistance of the roof insulation from R1 to R7 on top of the ceiling plaster board. It can be seen that annual energy usage is reduced significantly as R-values of insulation increases from 1 to 7 . However, this trend changes after R4 to become negligible between R6 and R7. Therefore, it can be concluded that there is an optimum point near R4. Consequently, using insulation with $\mathrm{R}$-value of 4 is the most efficient measure to retrofit the benchmark building without causing damage. 
Table 6. Changes in energy usage by adding different layer of insulation

\begin{tabular}{|l|c|c|c|}
\hline \multirow{2}{*}{ R-value of insulation } & \multicolumn{3}{|c|}{ Annual Energy Consumption MJ/m2 } \\
\cline { 2 - 4 } & Total & Heating & Cooling \\
\hline R 1 & 266.7 & 216.8 & 49.9 \\
\hline R 2 & 227.8 & 189.1 & 38 \\
\hline R 3 & 212.3 & 176.2 & 36.1 \\
\hline R 4 & 204.2 & 169.3 & 34.9 \\
\hline R 5 & 198.8 & 165 & 33.8 \\
\hline R 6 & 195.5 & 162 & 33.4 \\
\hline R 7 & 193 & 159.9 & 33.1 \\
\hline
\end{tabular}

\section{Improving Energy Consumption by using Different insulation on ceiling}

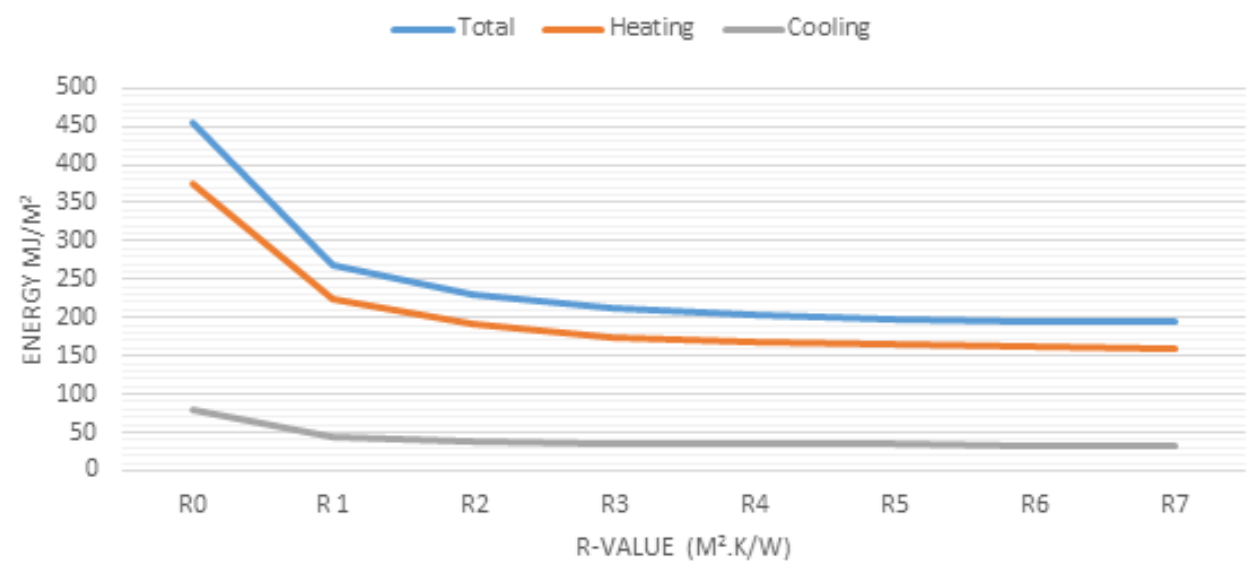

Figure 8. Graphical representation of energy improvement vs adding ceiling insulation

As considered in this study, the other sustainable solution for retrofitting is replacement of the windows with more sustainable material (Mode 10 and 11). As illustrated in Figure 9, Mode 10 and 11, 10 percent of the total energy saving can be achieved by windows replacement. Considering the cost and effectiveness of this technique, this amount of energy saving is negligible. Therefore, in comparison to adding R4 insulation in the ceiling, this method is more unreasonably costly and less effective. As illustrated in Figure 9, about $1.2 \%$ improvement has been achieved by installing floor insulation (Mode 12) which does not impact annual energy consumption significantly and can be considered negligible. Based on the star ratings generated by the software for each mode (Figure 10), it can be seen that the existing condition of the benchmark building has achieved 1.5 star rating while applying sustainable design principles in retrofitting the building has increased the star rating to 5.3 (Mode 9). 


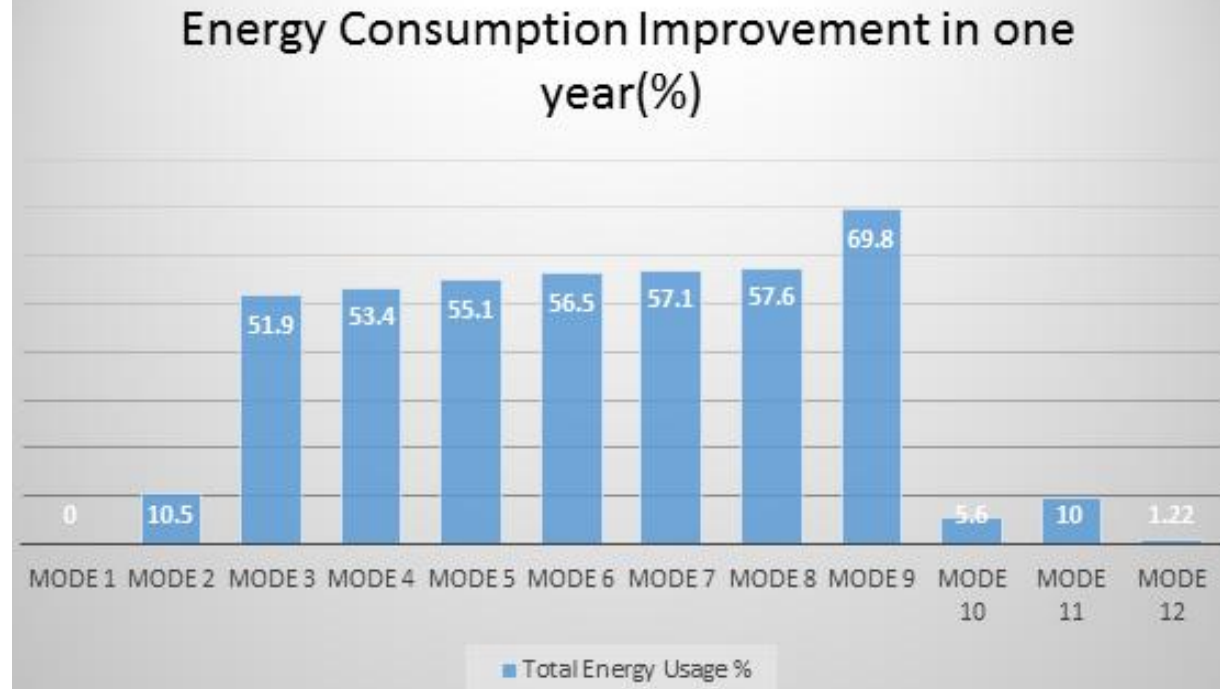

Figure 9. Total energy improvement per year (\%) for different modes

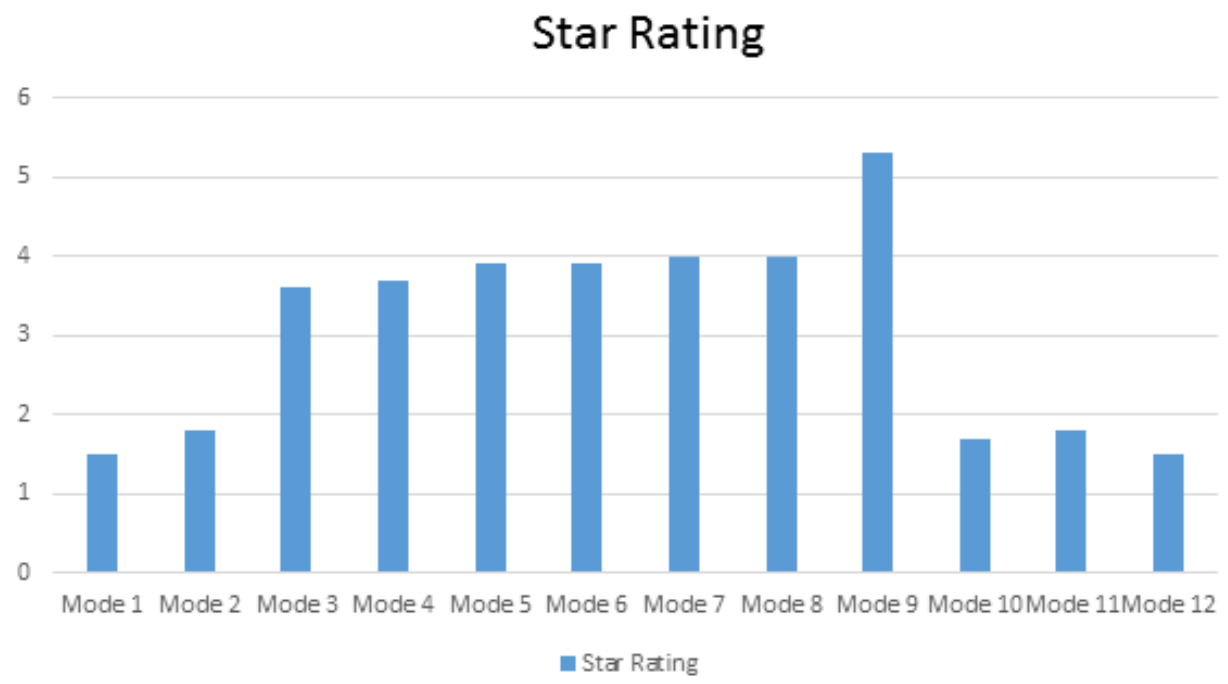

Figure 10. Maximum star rating achieved by different modes

In conclusion, using ceiling insulation in this building is the most feasible and effective sustainable retrofitting solution in comparison to the other proposed techniques due to its feasibility, simplicity and cost effectiveness.

\section{Conclusions}

In this study, effectiveness of 12 different sustainable energy retrofitting techniques and the impact of employing those methods on energy consumption of existing residential buildings have been examined and studied. Based on the research findings, it has become 
apparent that the most effective and feasible method of retrofitting the case study building is adding insulation layers at the ceiling level. Employing this method has increased the star rating of the benchmark building from 1.5 to near 4 without causing damage to the building which makes the method relatively cost-effective.

In addition, it has been observed that retrofitting of brick veneer walls can improve energy performance of brick veneer buildings. However, as the plasterboard needs to be removed and replaced during retrofitting process, using this technique increases the cost of retrofitting. It has been understood that based on the investigation results, refitting the floors does not have significant effects on energy consumption of buildings with slab foundation on the ground.

\section{References}

[1] ABCB (2014), "NCC Volume One Energy Efficiency Provisions”, Australian Building Codes Board, https://scavinutwal.files.wordpress.com/2015/10/abcb-energy-efficiency-handbook. pdf.

[2] CRES (2000), "Energy Audit Guide”, Centre for Renewable Energy Sources, Athens.

[3] Department of Industry (2013), "Your Home", 5th edition, Commonwealth of Australia.

[4] DEWHA (2008), "Energy Use in Australian Residential Sector", Department of the Environment, Water, Heritage and the Arts. Energy Rating (2014), Retrieved from http://www.energyrating.gov.au

[5] EPA (2013), Environmental Protection Agency, Retrieved from http://www.epa.gov/ climatechange/ghgemissions/global.html.

[6] IEA (2015), International Energy Agency, Retrieved from www.iea.org/about/faqs/ energyefficiency.

[7] Lyons, P. and Reardon, C. (2013), “Australia's Guide to Environmentally Sustainable Homes”, Retrieved from http://www.yourhome.gov.au.

[8] McGee, C. M., Partridge, E. Y., Carrard, N. R. and Milne, G. R. (2008), "Mainstreaming sustainable housing: policies and programs that work", Proceedings of the 2008 World Sustainable Building Conference, Melbourne, 1-8.

[9] Mithraratne, B. V. (2007), "Sustainable Living: the role of whole life costs and values", 1st edition, Elsevier Limited. 